Rev. Sauide pribl, S. Paulo, 19: 51-7, 1985.

\title{
EFICÁCIA DA VACINA SABIN EM CRIANÇAS SUBNUTRIDAS DA AMAZÔNIA*
}

\author{
Klaus E. Stewien** \\ Roger Shrimpton*** \\ Luís C. F. da Cunha** \\ Maria A. B. Alvim** \\ Lucia F. B. Viana** \\ Helyde A. Marinho*** \\ Cristovão A. da Costa***
}

\begin{abstract}
STEWIEN, K. E. et al. Eficácia da vacina Sabin em crianças subnutridas da Amazônia. Rev. Saúde públ., S. Paulo, 19: 51-7, 1985.

RESUMO: A eficácia da vacina Sabin foi determinada em 106 crianças normais e subnutridas da Amazônia, após a administraç̃o de uma e duas doses de vacina oral (trivalente). Após a aplicaçâo de uma dose de vacina, verificou-se que apenas $9 \%$ das crianças com subnutrição pregressa (crônica) e 43\% das crianças normais formaram anticorpos neutralizantes (protetores) contra dois ou três típos de poliovírus $(p=0,04)$. Após duas doses de vacina, os níveis de imunidade dos dois grupos de crianças estudadas acusaram, respectivamente, $32 \%$ e $75 \%$ (p = $0,001)$. Estes resultados mostram que a resposta imunitária à vacina Sabin foi sensivelmente inferior no grupo das crianças subnutridas, do que no das crianças normais. Em decorrência đisto, será necessário administrar um número maior de doses de vacina oral àquolas crianças, a fim de que níveis satisfatórios de imunidade contra a poliomielite sejam atingidos em toda a populaçấo infantil.
\end{abstract}

UNITERMOS: Vacinação Sabin. Poliomielite, vacinaçăo. Desnutriçã̃o. Imunizaçâo.

\section{INTRODUÇÃO}

Estudos realizados em diversas partes do mundo revelam que a eficácia da vacina oral contra a poliomielite sofre variações geográficas $^{6}$. Em países de clima temperado, a ex. periência mostra que com a administração de duas doses de vacina oral (trivalente) se costuma imunizar mais de $80 \%$ dos individuos contra os 3 tipos de vírus da poliomieli$\mathrm{te}^{9,14}$. Este resultado altamente satisfatório, entretanto, deixou de ser observado em muitas regioes de clima tropical, onde pesquisas bem controladas têm demonstrado que igual número de doses de vacina leva a níveis de imunidade inferiores, da ordem de apenas $50 \% \%^{8}, 12,13,16,17,19$

Niveis insuficientes de imunidade tam. bém foram encontrados em nosso meio, particularmente em camadas pobres da popu-

Os autores dedicam este trabalho à memória do Prof. Victório Barbosa, a quem o estudo da poliomielite em nosso meio muito deve.

- Pesquisa realizada com auxflio financeiro do Conselho Nacional de Desenvolvimento Científico e Tecnológico (CNPq-PIN Trópico Omido, Proc. no 0170.0153/81).

* Do Departamento de Patologia do Centro de Ciências da Saúde da Universidade Federal do Maranhão - Caixa Posta 675 - 65.000 - Sáo Luís, MA - Brasil.

*** Do Instituto Nacional de Pesquisas da Amazônia (INPA) - Caixa Postal 478 - 69.000 - Manaus, AM - Brasil. 
STEWIEN, K.E. et al. Eficácia da vacina Sabin em crianças subnutridas da Amazônia. Rev. Saride públ, S. Paulo, 19: 51-7, 1985.

lação infantil ${ }^{1,3,4,21}$. Em decorrência disto, numerosos casos de paralisia infantil foram registrados em crianças que tinham sido vacinadas com uma a quatro doses de vacina oral, tanto em nosso país quanto em outros países de clima tropical ${ }^{2} 11,15$.

Diversos fatores foram apontados para ex. plicar os baixos níveis de imunidade freqüentemente observados nestes países. Dentre estes fatores, amplo estudo realizado na Åfrica confirmou a interferência viral, causada pela presença de outros enterovírus na mucosa intestinal, e descobriu uma substância, presente no aparelho digestivo das crianças, capaz de inibir a multiplicação dos vírus vacinais ${ }^{7}$. Verificou-se naquele estudo que a substância inibidora leva a um número muito maior de falhas vacinais do que a interferên. cia viral. Contudo, sua origem ainda não é conhecida. Como tal substância só foi encontrada em grupos populacionais de precárias condiçōes de vida, existe a possibilidade de que esteja associada com a subnutrição.

A hipótese de que a subnutrição protéico-calórica poderia interferir na resposta imunitária à vacina Sabin foi levantada por Plotkin, em $1967^{18}$. Recente pesquisa, realizada em pequeno número de crianças desnutridas do 30 grau, revelou que a formaçáo dos anticorpos secretórios da classe IgA estava prejudicada em uma parte delas ${ }^{5}$.

Com a finalidade de ampliar os conhecimentos sobre o assunto ora exposto, que pa. rece ser de fundamental importância para implementar os programas de vacinação contra a poliomielite no Brasil, decidiu-se in vestigar o problema da resposta imunitária em crianças que sofrem de subnutrição protéico-calórica do 10 e 20 graus. Este trabalho apresenta os resultados de imunização de crianças normais e subnutridas da Amazônia, após a administração de uma e duas doses de vacina oral (trivalente).

\section{MATERLAL E MÉTODOS}

\section{Grupo de crianças estudadas}

Participou da presente pesquisa um total de 106 crianças de 5 a 14 meses de idade, procedentes das cidades de Manaus, Amazo- nas, e de São Luis, Maranhão. As crianças pertenciam à classe sócio-econômica pobre. As informações necessárias ao estudo foram obtidas mediante o preenchimento de questionários submetidos às mães das crianças, abrangendo os seguintes ítens: nome, data de nascimento, procedência, número de doses e data de administração da vacina oral. Todas as crianças examinadas receberam a vacina oral nos dias da Campanha Nacionaly de Vacinação contra a Poliomielite.

\section{Exames antropométricos}

As crianças foram medidas e pesadas por ocasião da colheita das amostras de sangue e classificadas em normais e subnutridas de acordo com o padrão de crescimento de Harvard, segundo as recomendaçס̃es de Waterlow ${ }^{22}$. Todas as crianças que apresentavam uma estatura de $94 \%$ a $85 \%$ da norma foram classificadas no grupo das subnutridas - na. nismo de 10 e 20 grau - e aquelas que mediam $95 \%$ ou mais da norma formaram o grupo das crianças normais. Foram excluídas da amostra as crianças que apresentavam uma relação peso por altura menor do que $90 \%$ da norma (10, 2 \% e 30 graus de magreza). Também não foram incluídas no presen. te estudo aquelas crianças que apresentavam nanismo do 39 grau.

\section{Colheita e preparo das amostras de sangue}

As amostras de sangue foram colhidas das crianças 16 a 18 dias após a vacinação por extração digital, mediante o uso de lancetas descartáveis (Becton, Dickinson). De cada criança foram extraídas 6 a 8 gotas de sangue, colhidas em tubos de Kline esteriliza. dos. Logo após a colheita, as amostras de sangue foram transportadas para o labora. tório, onde se separava o soro do coágulo com o auxflio de uma pipeta automática. De cada amostra se obtinha, via de regra, um total de 200 microlitros de soro, quantida. de suficiente para repetidas provas de do. sagem de anticorpos pela microtécnica. Os soros foram congelados a $-20^{\circ} \mathrm{C}$ até a reali. zação das provas de neutralização. As amostras de soro obtidas em Manaus foram trans. portadas por aviáo, em recipientes contendo 
STEWIEN, K.E. et al. Efić́cia da vacina Sabin em crianças subnutridas da Amazônia. Rev. Saúde públ, S. Paulo, 19: 51-7, 1985.

gelo seco, para o Laboratório de Virologia da Universidade Federal do Maranhão, onde foram realizadas todas as provas de dosagem de anticorpos.

\section{Provas de neutralização}

Os anticorpos neutralizantes (protetores) para os poliovírus dos tipos 1,2 e 3 foram dosados pela microtécnica (Diagnostic Procedures for Viral and Rickettsial Diseases) ${ }^{20}$, utilizando microplacas descartáveis de $96 \mathrm{ca}$ vidades. Em todas as provas foram utilizadas as estirpes atenuadas de Sabin dos tipos 1, 2 e 3. As misturas de vírus e soro, assim como os controles de vírus, foram submetidos a um período de incubação de meia hora, à temperatura ambiente, e de $18 \mathrm{~h}$ a $4{ }^{\circ} \mathrm{C}$, antes da adição da suspensáo de células GMK AH-1. A leitura dos resultados era realizada após incubação de $48 \mathrm{~h}$ a $37^{\circ} \mathrm{C}$, com o auxílio de um microscópio biológico invertido.

\section{Análise estatistica}

As diferenças encontradas entre os resultados dos dois grupos de crianças examinadas foram submetidas à análise estatística, empregando o Teste Exato de Fischer, a nível de $5 \%$.

\section{RESULTADOS}

A Tabela 1 mostra, para os dois grupos de crianças examinadas, a prevalência de anticorpos protetores contra $0,1,2$ e 3 tipos de poliovírus, após a administração de 1 dose de vacina oral (trivalente). Observa-se que $45,5 \%$ das crianças subnutridas não formou anticorpos de nenhum tipo, permanecendo susceptível aos 3 tipos de vírus da poliomielite. Já no grupo das crianças normais (grupo controle), isto ocorreu em apenas $16 \%$. Em contrapartida, a proporção de crianças que apresentou anticorpos protetores contra 2 ou 3 tipos de poliovírus ficou em apenas $9 \%$ no grupo das crianças subnutridas, contra $43 \%$ no grupo de crianças normais. Esta diferença é significante pelo Teste Exato de Fischer (valor de $p=0,037$ )

A Tabela 2 apresenta os resultados de imunização após a administração de duas doses de vacina oral. Verifica-se que ainda restou uma parcela de $18 \%$ de crianças subnutridas que não respondeu a nenhuma das duas doses de vacina administradas, deixando de formar anticorpos neutralizantes contra qualquer dos 3 tipos de poliovírus. No grupo controle, esta proporção foi de apenas $3 \%$. Por outro lado, a proporção de crianças que se imunizaram contra 2 ou 3 tipos de poliovírus foi de $32 \%$ no grupo das subnutridas, contra $75 \%$ no grupo das normais. Esta diferença também é estatisticamente significante (valor de $p=0,001$ ).

As Figs. 1 e 2 mostram os níveis de imu-

T A B E L A 1

Prevalência de anticorpos protetores contra um ou mais tipos de poliovírus em crianças da Amazônia, após a administração de uma dose de vacina oral trivalente. Manaus e Săo Luís, 1982.

\begin{tabular}{lrccc}
\hline \multirow{2}{*}{$\begin{array}{l}\text { Prevalência } \\
\text { de }\end{array}$} & \multicolumn{4}{c}{ Crianças com uma dose de vacina } \\
\cline { 2 - 5 } Anticorpos* & No & Normais & $\%$ & Com Nanismo \\
\hline Contra 0 tipo & $6 / 37$ & 16 & $5 / 11$ & 45,5 \\
Contra 1 tipo & $15 / 37$ & 41 & $5 / 11$ & 45,5 \\
Contra 2 tipos & $9 / 37$ & 24 & $1 / 11$ & 9 \\
Contra 3 tipos & $7 / 37$ & 19 & $0 / 11$ & 9 \\
$2+3$ tipos & $16 / 37$ & $\underline{43}$ & $1 / 11$ & 9 \\
\hline
\end{tabular}

* Crianças com anticorpos protetores na dil. 1:8. 
STEWIEN, K.E. et al. Efićácia da vacina Sabin em crianças subnutridas da Amazônia. Rev. Saride pübl., S. Paulo, 19: 51-7, 1985 .

TA B E L A 2

Prevalência de anticorpos protetores contra um ou mais tipos de poliovírus em crianças da Amazônia, após a administração de duas doses de vacina oral trivalente. Manaus e São Luís, 1982.

\begin{tabular}{lrrrr}
\hline \multirow{2}{*}{$\begin{array}{l}\text { Prevalência } \\
\text { de }\end{array}$} & \multicolumn{4}{c}{ Crianças com duas doses de vacina } \\
\cline { 2 - 5 } Anticorpos* & No & Normais & $\%$ & Com Nanismo \\
\hline Contra 0 tipo & $1 / 36$ & 3 & $4 / 22$ & \% \\
Contra 1 tipo & $8 / 36$ & 22 & $11 / 22$ & 18 \\
Contra 2 tipos & $15 / 36$ & 42 & $3 / 22$ & 50 \\
Contra 3 tipos & $12 / 36$ & 33 & $4 / 22$ & 14 \\
$2+3$ tipos & $27 / 36$ & $\underline{75}$ & $7 / 22$ & $\underline{32}$ \\
\hline
\end{tabular}

* Crianças com anticorpos protetores na dil. 1:8.

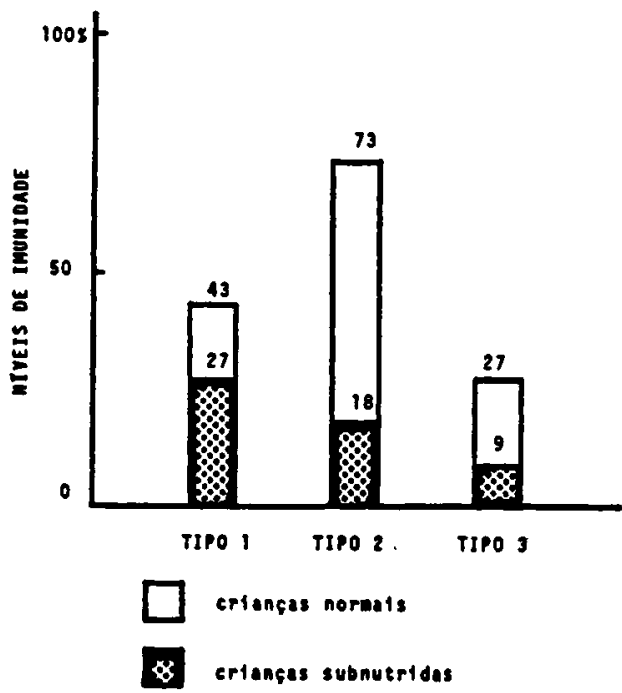

Fig. 1 - Níveis de imunidade contra os poliovírus dos tipos 1, 2 e 3, em crianças normais e subnutridas da Amazônia, após a administraçz̃o de uma dose da vacina oral trivalente -1982 .

nidade para cada um dos 3 tipos de vírus da poliomielite, respectivamente após a administração de uma ou duas doses de vacina oral. Verifica-se que as crianças subnutridas

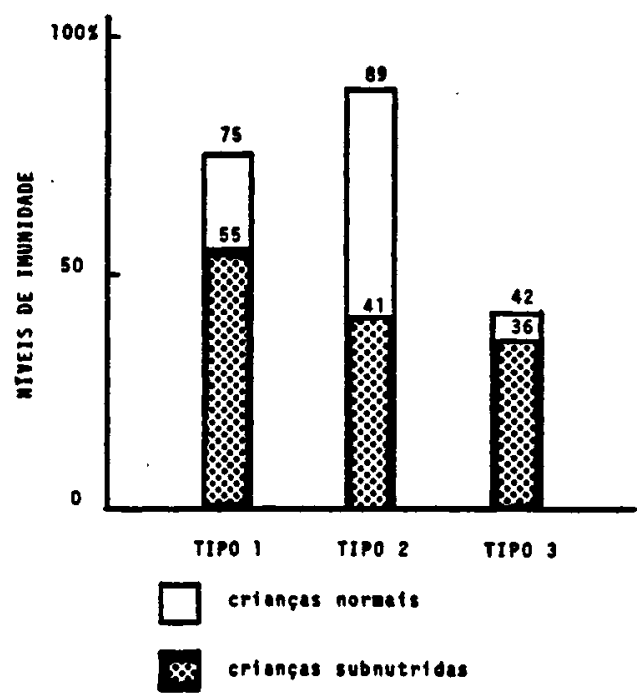

Fig. 2 - Níveis de imunidade contra os poliovirus dos tipos 1,2 e 3 em crianças normais e subnutridas da Amazônia, após a administração de duas doses da vacina oral trivalente -1982 .

exibem níveis de imunidade invariavelmente menores do que as normais, tanto ap6s a administração de uma dose, quanto de duas doses de vacina. 
STEWIEN, K.E. et al. Eficácia da vacina Sabin em crianças subnutridas da Amazônia. Rev. Saúde públ., S. Paulo, 19: 51-7, 1985.

Após a aplicação de duas doses de vacina, a Fig. 2 mostra que as crianças normais atin. gem níveis de imunidade da ordem de $75 \%$, $89 \%$ e $42 \%$, respectivamente, contra os po. liovírus dos tipos 1,2 e 3 , enquanto as crian. ças subnutridas chegam apenas a $55 \%, 41 \%$ e $36 \%$.

\section{DISCUSSĀO}

Os resultados obtidos no presente traba. lho mostram que os niveis de imunidade encontrados no grupo de crianças subnutridas são significativamente menores do que aqueles observados no grupo das crianças normais. Isto se deu tanto após a administração de uma dose de vacina oral (trivalente) quanto após a aplicação de duas doses desta vacina.

A diferença encontrada entre os níveis de imunidade dos dois grupos estudados náo pode ser atribuída a fatores de ordem operacional, de vez que tanto as crianças normais quanto as subnutridas foram vacinadas no mesmo dia - Dia Nacional de Vacinação contra a Poliomielite - e, portanto, em idênticas condições e com o mesmo lote de vacina. Também não é de se supor que os resul. tados encontrados tenham sido afetados pelo fator interferência viral, já que as crianças dos dois grupos examinados pertenciam ao mesmo segmento populacional, residindo nos mesmos distritos das cidades de Manaus e São Luis. Desta forma, tanto as crianças normais quanto as subnutridas estiveram expostas aos enterovírus que circulam na mesma área geográfica.

Estas consideraçס̃es, portanto, nos levam a admitir que a subnutrição protéico-calóri. ca tem um efeito antagônico sobre a resposta imunitária à vacina oral, provocando uma diminuição nos níveis de imunidade contra a poliomielite em crianças que sofrem de nanismo na região amazônica. Em face aos resultados encontrados, é bem provável que a subnutrição também seja o fator preponde. rante, na origem das falhas vacinais, em outras regioes de clima tropical, que apresentam populações de elevado grau de pobreza.

Em trabalho anterior, Chandra (1975) havia demonstrado, em pequeno número de crianças normais e subnutridas do 30 graú, que a formação de anticorpos secretórios da classe IgA se deu com frequêencia menor no grupo das crianças subnutridas. Também a prevalência dos anticorpos séricos estava diminuída neste grupo de crianças, embora a diferença em relação ao grupo de crianças normais não fosse estatisticamente significante.

Espera-se que as observaçסes feitas tenham ampla repercussão e venham contribuir para implementar os programas de vacinação oral em nosso meio, para que a paralisia infantil não possa escapar ao controle ora alcançado. E preciso ter em conta que a nossa população pré-escolar é constituída de elevado número de crianças subnutridas, principalmente do 1 e e 20 graus. Segundo Horner $(1980)^{10}$, nada menos do que $53 \%$ das crianças de 0 a 7 anos de idade sofre de subnutrição. Verifica-se também que em nossa população infantil a subnutrição pregressa (crônica) é oito vezes superior à subnutrição aguda (recente).

Os niveis de imunidade encontrados no presente trabalho, após a aplicação de duas doses de vacina oral (Tabela 2 e Fig. 2), mostram que um número maior de doses de va. cina será necessário para completar o pro. cesso de imunização em nossas crianças, particularmente naquelas que sofrem de desnutrição. Em trabalho anterior, Barbosa e Stewien (1978) ${ }^{4}$ mostraram, em um grupo de crianças paulistas, que com 3 doses de vacina oral se atinge o nível mínimo desejável de $75 \%$ de imunes contra os 3 tipos de polioví. rus. Este nivel, verificado em crianças normais, provavelmente não será atingido pelas crianças subnutridas, a não ser que se au. mente o número de doses de vacina.

Estudos soro-epidemiológicos, realizados na India por John (1976) ${ }^{11}$ e no Brasil por Barbosa e col. $(1977)^{3}$, revelam que níveis satisfatórios de imunidade somente foram alcançados após a administração de 5 doses de vacina Sabin à população infantil. Conseqüentemente, estas 5 doses deveriam passar a ser recomendadas em todos os programas de vacinação oral no Brasil. 
STEWIEN, K.E. et al. Eficácia da vacina Sabin em crianças subnutridas da Amazônia. Rev. Saride públ., S. Paulo, 19:51-7, 1985.

STEWIEN, K.E. et al. [The efficacy of oral polio vaccine in malnourished Amazonian children]. Rev. Saúde públ, S. Paulo, 19: 51-7, 1985.

ABSTRACT: Various hypotheses have been proposed to explain the diminished efficacy of the oral polio vaccine in underdeveloped tropical regions. In this study, the influence of mild to moderate chronic malnutrition on the development of antibodies to the 3 types of polioviruses was investigated in Brazilian Amazonian children. Vaccines were administered to 106 normal and stunted children, between 5 to 14 months of age, who were not suffering from acute malnutrition (wasting), in poor peri-urban slum areas of Manaus (AM) and São Luis (MA) during the National Poliomyelitis Vaccination Campaigns of 1981 and 1982. Two weeks after vaccination, blood was collected by digital puncture and the prevalence of neutralizing antibodies for the 3 types of poliovinuses was determined in serum at a dilution of $1: 8$. In children who had received one dose of the vaccine, $43 \%$ of normal children had antibodies to 2 or 3 types of polioviruses, against only $9 \%$ of stunted children $(p=.04)$. In children who had received 2 doses of vaccine, $75 \%$ of normal children but only $32 \%$ of stunted children had formed antibodies to 2 or 3 types of polioviruses $(p=.001)$. These results suggest that mildly to moderately stunted children have an impaired immune response to the oral poliomyelitis vaccine and that more than 2 doses of vaccine are necessary to achieve satisfactory immunity levels in poor tropical communities where such malnutrition is common.

UNITERMS: Poliovirus vaccine, oral. Poliomyelitis. Nutrition disorders. Immunization.

\section{REFERENCIAS BIBLIOGRÅFICAS}

1. BARBOSA, V. \& STEWIEN, K. E. Estado imunitário relativo à poliomielite das crianças de 0-12 anos, residentes no municfpio de São Paulo, Brasil e assistidas pelo Hospital Menino Jesus. Rev. Saúde públ., S. Paulo, 9:137-53, 1975.

2. BARBOSA, V. \& STEWIEN, K. E. Aspectos de importância para a vigilância epidemiológica da poliomielite na cidade de S5o Paulo, Brasil. Rev. Saúde pribl., S. Paulo, 14: $557-68,1980$.

3. BARBOSA, V. et al. Estado vacinal, tipo de habitação e nível cultural da mãe e sua relação com o estado imunitário contra a poliomielite em uma amostra de escolares do município de São Paulo. Rev. Saride públ., S. Paulo, 9: 330-7, 1977.

4. BARBOSA, V. et al. Nível de imunidade contra a poliomielite em um grupo de crianças vacinadas de acordo com o calendário oficial de imunização (São Paulo, Brasil) Rev. Sauide puibl., S. Paulo, 12: 326-32, 1978.

5. CHANDRA, R. K. Reduced secretory antibo. dy response to live attenuated measles and poliovinus vaccines in malnourished children. Brit. med. J., 2: 583-5, 1975.
6. COCKBURN, W. C. \& DROZDOV, S.G. Poliomyelitis in the world. Bull. Whd Hlth Org. 42: 405-17, 1970.

7. DÖMÖK, 1, et al. Factors affecting the efficacy of live poliovirus vaccine in warm climates. Bull. Wld Hlth Org., 51: 333-47, 1974.

8. FRANKLIN, G. C. \& ROBERTSON, M. J. A mass vaccination campaign against poliomyelitis using the Sabin oral vaccine. Publ. Hith, 79: 81-99, 1975.

9. HARDY, G. E. et al. Trivalent oral poliovirus vaccine: a comparison of two infant immunization schedules. Pediatrics, 45: 444-8, 1970.

10. HORNER, M.R. Estado nutricional de criancas brasileiras de 0-7 anos de idade. Revisão de dados recentes. Brasília, UNICEF/ MPAS, 1980. [Documento interno]

11. JOHN, T.J. Antibody response of infants in tropics to five doses of oral poliovaccine. Brit. med. J., 1: 812, 1976.

12. JOHN, T.J. \& JAYBAL, P. Oral polio vaccination of children in the tropics. I. The poor 
STEWIEN, KE. et al. Eficácia da vacina Sabin em crianças subnutridas da Amazônia. Rev. Saúde públ., S. Paulo, 19: 51-7, 1985.

seroconversion rates and the absence of viral interference. Amer. J. Epidemiol., 96: $263-9,1972$

13. LEE, L.H. Prevention of poliomyelitis in Sin gapore by live vaccine. Brit. med. J., 1: $1077.80,1964$.

14. LENNARTZ, H. \& FISCHER, $\mathrm{K}$. Uberwachung der Poliomyelitsverbreitung in Hamburg.Arch. Hyg., Berlin, 151 : 757-61, 1967.

15. MELNICK, J.L. Combined use of live and killed vaccines to control poliomyelitis in tropical areas. Develop. biol. Stand., 47: 265-73, 1981.

16. MINISTRY OF HEALTH, Nigeria. Poliomyelitis Commission of the Western Region. Poliomyelitis vaccination in Ibadan, Nigeria, during 1964 with oral vaccine (Sabin strains). Bull. Whd Hlth Org., 34:865$76,1966$.

17. NATEGH, $\mathbf{R}$ et al. Mass trivalent oral polio vaccination in primary school age children in Teheran. Trop. geogr. Med., 22: 303-6, 1970.

18. PLOTKIN, S. Discussions. In: International Conference on Virus Vaccines Against Viral and Rickettsial Diseases of Man, $1^{\text {st }}$, Washington, D.C., 1966. Proceedings. Wa- shington, D.C., Pan American Health Organization, 1967. (PAHO - Scient. publ, 147).

19. SANGKAWIBHA, N. et al. Antibody response and virus excretion after oral vaccination with trivalent live poliomyelitis vaccine. $J$. med. Ass Thatland, 52:701-12, 1969.

20. SCHMIDT, N.J. Tissue culture technics for diagnostic virology. In: Lennette, E.H. \& Schmidt, N.J., ed. Diagnostic procedures for viral and rickettsial diseases, $4^{\text {th }}$ ed. New York, American Public Health Association, 1969, p. 78-176.

21. STEWIEN, K.E. et al. Niveis de imunidade contra a poliomielite em uma amostra de escolares do munić́pio de São Paulo, Brasil. Rev. Saúde públ., S. Paulo, 11:270-8, 1977.

22. WATERLOW, J.C. Classification and definition of proteinenergy malnutrition. In: Beaton, G.H. \& Bengoa, J.M., ed. Nutrition in preventive medicine. Geneva, World Health Organization, 1976. p.530-2.

Recebido para publicaçäo em 17/10/1984. Aprovedo para publicação em 17/12/1984. 